\title{
ON A CERTAIN CLASS OF MEROMORPHIC FUNCTIONS ASSOCIATED WITH A DIFFERENTIAL OPERATOR
}

\author{
Ao-En AND SHU-HAI Li
}

\begin{abstract}
In this paper, we introduce and investigate a new class of meromorphic functions defined by a differential operator. For this class, we obtain coefficient inequality, distortion inequality, radius of close-to-convex, starlikeness and convexity, extreme points and integral means inequality.
\end{abstract}

Mathematics subject classification (2010): 30C45.

Keywords and phrases: meromorphic functions, differential operator, coefficient inequality, distortion inequality, radius, extreme points, integral means inequality.

\section{REFERENCES}

[1] J. DzIOK, Classes of meromorphic functions defined by the hadamard product, International Journal of mathematics and mathematics sciences, Volume 2010, Article ID 302583, 11 pages.

[2] Ch. Pommerenke, On meromorphic starlike functions, Pacific J. Math. 13 (1963), 221-235..

[3] W. C. Poyster, Meromorphic starlike multivalent functions, Trans. Am. Math. Soc. 107 (1963), 300-308

[4] J. E. Miller, Convex meromorphic mapping and related functions, Proc. Amer. Math. Soc. 25 (1970), 220-22.

[5] S. K. BAJPAI, A note on a class of meromorphic univalent functions, Rev. Roum. Math. Pures Appl. 22 (1977), 295-297.

[6] M. L. Mogra, T. R. Reddy, O. P. JuneJA, Meromorphic univalent functions with positive coeffcients, Bull. Austral. Math. Soc. 32 (1985), 161-176.

[7] N. E. CHO, S. H. LEE, S. OWA, A class of meromorphic univalent functions with positive coefficients, Kobe J.Math. 4 (1987), 43-50.

[8] M. K. AouF, A certain subclass of meromorphically starlike functions with positive coefficients, Rend. Mat. 9 (1989), 225-235.

[9] N. E. CHO, On certain class of meromorphic functions with positive coefficients, J. Inst. Math. Comput. Sci. 3, 2 (1990), 119-125.

[10] M. K. Aouf, On a certain class of meromorphically univalent functions with positive coefficients, Rend. Mat. 11 (1991), 209-219.

[11] B. A. Uralegaddi, C. Somanatha, New criteria for meromorphic starlike univalent functions, Bull. Austral. Math. Soc. 43 (1991), 137-140.

[12] H. M. SRIVAstava, S. OWA, Current topics in analytic functions theory, World Scientific, Singapore, 1992.

[13] N. E. CHO, I. H. KIM, Inclusion properties for certain classes of meromorphic functions associated with the generalized hypergometric function, Applied Mathematics and Computation 187 (2007), 115121.

[14] N. E. CHO, K. InAYATNOOR, Inclusion properties for certain classes of meromorphic functions associated with the Choi-Saigo-Srivastava operator, J. Math. Anal. Appl. 320 (2006), 779-786.

[15] Shao-Mou Yuan, Zai-Ming Liu, H. M. Srivastava, Some inclusion relationships and integralpreserving properties of certain subclasses of meromorphic functions associated with a family of integral operators, J. Math. Anal. Appl. 337 (2008), 505-515. 
[16] Krzysztof, Piejko, Janusz Sokol, Subclasses of meromorphic functions associated with the Cho-Kwon-Scrivastava operators, J. Math. Anal. Appl. 337 (2008), 1261-1266.

[17] WagGas Galib Asthan, Subclass of meromorphic functions with positive coefficients defined by Ruscheweyh derivative II, Surveys in Math. and its Appl. 3 (2008), 67-77.

[18] B. A. Frasin, M. Darus, On certain meromorphic functions with positive coefficients, Southeast Asian Bull. Math. 28 (2004), 615-623.

[19] F. Ghanim, M. Darus, On certain subclass of meromorphic univalent functions with fixed residue, Far East J. Math. Sci. 26 (2007), 195-207.

[20] F. GHANIM, M. DARUS, A new subclass of uniformly starlike and convex functions with with negative coefficients II, Int. J. Pure Appl. Math. 45, 4 (2008), 559-572.

[21] R. M. El-Ashwah, M. K. Aouf, Hardmard product of certain meromophic starlike and convex functions, Comput. Math. Appl. 57 (2009), 1102-1106.

[22] F. GHANim, M.Darus. On a certain subclass of meromorphic univalent functions with fixed second positive coefficients, Sruveys in Mathematics and its Applications 5 (2010), 49-60.

[23] S. H. LI, H.Tang. Certain new classes of analytic functions defined by using the Salagean operator, Bull. Math. Anal. Appl. 24 (2010), 62-75.

[24] J. E. Littlewood, On inequalities in the theory of functions, Proc. London Math. Soc. 23 (1925), 481-519. 